\title{
Parametric Study on Mutual Coupling Reduction for MIMO Future 5G Antennas
}

\author{
H. Yon, N. H. Abd Rahman, M.A Aris, M. H. Jamaluddin, H. Jumaat
}

\begin{abstract}
This paper presents the development of a compact Multiple Input Multiple Output (MIMO) antenna using new structure integrated with $\mathrm{C}$ shaped parasitic element for mutual coupling reduction and antenna isolation improvement. The antenna has been designed to resonate at $16 \mathrm{GHz}$ for future $5 \mathrm{G}$ mobile band. The separation of the antennas has been set from $0.5 \lambda_{0}$ to $0.26 \lambda_{0}$ to investigate the mutual coupling between dual antenna elements. The novel $C$ shaped parasitic element has been located around the main radiating patch with $1 \mathrm{~mm}$ in width to reduce the mutual coupling between the dual element antennas. Meanwhile, the separation distance of $0.32 \lambda_{0}$ between the antennas has been chosen for the final antenna design due to its good performance. By using the novel $\mathrm{C}$ shaped parasitic element, the antenna isolation have reduced from $-11.77 \mathrm{~dB}$ for without

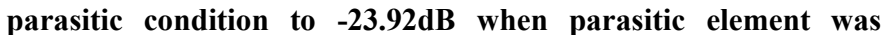
included. The result shows $\mathbf{2 5 . 7 9 \%}$ isolation improvement has been achieved for antenna with $C$ shaped parasitic element. Furthermore, by introducing the parasitic element, the bandwidth have been improved $32.71 \%$ from the design without parasitic element. The antenna was simulated and optimized at $16 \mathrm{GHz}$ using Computer Simulation Technology (CST) with permittivity, $\varepsilon_{r}=2.2$ and thickness, $h=\mathbf{1 . 5 7} \mathrm{mm}$ on Rogers RT-Duroid 5885 substrate. The antennas are matched at their corresponding frequency of operations. The simulation results have shown that the antenna works well.
\end{abstract}

Index Terms - MIMO, Parasitic element, CST, Rogers.

\section{INTRODUCTION}

$\mathrm{W}$ IRELESS systems for the future $5 \mathrm{G}$ cellular system are increasingly proposing the utizalition of the high frequency band spectrum due to growing need for support huge number of user and applications. The current and incoming $5 \mathrm{G}$ network requires communication systems that can handle larger data rates with high speed and consistent quality of transmission. With these requirements, advanced wireless communication Multiple Input Multiple Output (MIMO) technology plays a key role to meet the requirements of high quality and high data rate communication systems. In 1990, MIMO technology was proposed as a solution to overcome data rate limit by single input single output (SISO)[1].

This manuscript is submitted on $10^{\text {th }}$ October 2019 and accepted on $24^{\text {th }}$ March 2020. H. Yon, N. H. Abd Rahman, M.A Aris and H. Jumaat are with the Faculty of Electrical Engineering, Universiti Teknologi MARA, 40450 Shah Alam, Selangor (e-mail:hamizan2816@uitm.edu.my)

M. H. Jamaluddin is with Universiti Teknologi Malaysia (UTM).

1985-5389/C 2021 The Authors. Published by UiTM Press. This is an open access article under the CC BY-NC-ND license (http://creativecommons.org/ licenses/by-nc-nd/4.0/).
In order to develope MIMO antenna system, it is requires multiple antenna elements at the transmitter and the receiver to achieve a linear increase in the data rate with an increase the number of antennas. However, it is a big challenge to keep multiple number of antennas within a small and compact space due to the mutual coupling developed between the antenna elements[2]. This mutual coupling arises due to the interaction of radiations from closely spaced antennas and also due to the surface currents flowing on the ground plane[3]. This will make field correlation and mutual coupling increase and thus will degrade the diversity performance of the MIMO antenna system[4].

The most recent research on MIMO antenna design is mainly focusing on mitigating the effects of mutual coupling and investigating various efficient techniques to reduce it. Evaluating and monitoring the antenna surface current was one of the key factors in determining the amount of mutual coupling between the antennas. Some of the MIMO antenna designers have introduced parasitic element[5], defected ground structure (DGS)[6], metamaterial[7], slot[8], neutralization line[9], stacked configuration[10], orthogonal polarization[11], metallic wall[12], decoupling structure[13], and hybrid structure[14] to reduce the mutual coupling in MIMO antenna design.

The easiest way to reduce mutual coupling and improve isolation between antennas is by adjusting the antenna distance to be more than $\lambda / 2$ as mentioned in[15]. Although this method gives good isolation between multiple antennas, this configuration needs to extend distance between antenna and so that there is an increase the antenna size. Meanwhile in [16] the researcher have design DGS to reduce mutual coupling. However, designing the DGS will shifted the resonant frequency, due to higher coupling by the DGS structure. Meanwhile, in [17] good isolation between multiple antenna has been achieve using parasitic element.

In this preliminary research works, the mutual coupling is reduced by introducing a novel $\mathrm{C}$ shaped parasitic element around the radiating patch structure. The performance of the antenna has been investigated between without and with parasitic element to observe the effects of parasitic structure to the antenna isolation performance. The isolation has been improved $25.79 \%$ between with and without parasitic element, respectively. 


\section{DESIGN OF DUAL ELEMENT MIMO ANTENNA}

The design of the proposed antennas are shown in Figure 1 and Figure 2, respectively. The radiating element of the antenna structure is located at the top layer while the full ground plane is at the bottom layer. Comparison is made between two antenna structures; a circular patch and a circular patch with $\mathrm{C}$ shaped parasitic element. The MIMO antenna has a size of $15 \mathrm{~mm} \times 30 \mathrm{~mm}$ for both designs with and without parasitic element. Table 1 shows the parameters of the final optimized antenna structure. The purpose in designing the $\mathrm{C}$ shaped parasitic element on the antenna design is to improve antenna's mutual coupling for future $5 \mathrm{G}$ technology[18]. The antenna has been designed and optimized at $16 \mathrm{GHz}$ based on the future $5 \mathrm{G}$ mobile band as mentioned in[19] and has been simulated on RT Duroid 5880 substrate with permittivity of 2.2 , loss tangent of 0.002 and thickness (h) of $1.57 \mathrm{~mm}$.

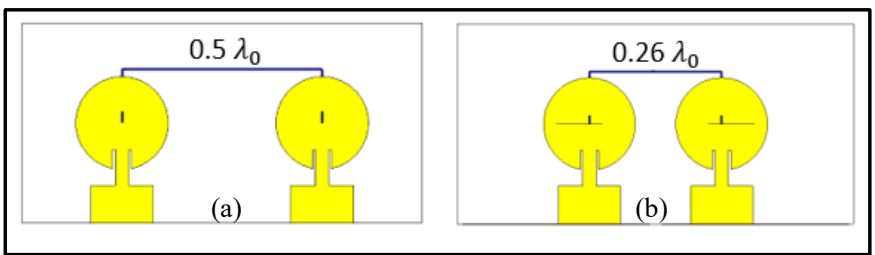

Fig. 1. MIMO antenna without $C$ shaped parasitic element (a) $0.5 \lambda_{0}$ (b) $0.26 \lambda_{0}$

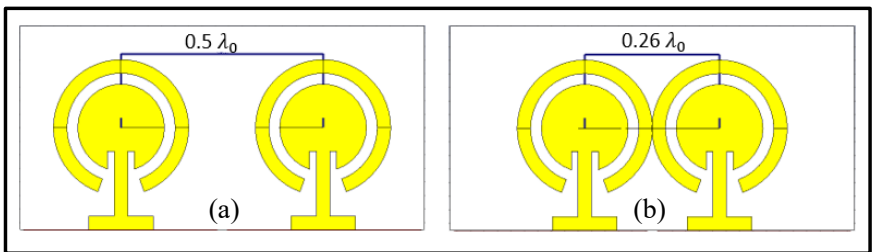

Fig. 2. MIMO antenna with parasitic element (a) $0.5 \lambda_{0}$ (b) $0.26 \lambda_{0}$

TABLE 1

ANTENNA PARAMETERS

\begin{tabular}{|c|c|}
\hline Parameters & Value [mm] \\
\hline Diameter of patch & 3.22 \\
\hline Length of feed & 2 \\
\hline Length of substrate & 30 \\
\hline Material thickness & 1.57 \\
\hline $\begin{array}{c}\text { Width of parasitic } \\
\text { element }\end{array}$ & 1 \\
\hline Width of feed & 4.77 \\
\hline Width of substrate & 15 \\
\hline
\end{tabular}

The simulated reflection coefficients, $S_{11}$ are shown in Figure 3 and the antenna isolations are shown in Figure 4 for both designs. The antenna has shown good response within the selected frequency range. The simulated impedance bandwidth shows good coverage around the resonant frequency of $16 \mathrm{GHz}$. However, significant shift in $S_{11}$ is shown at a distance of $0.26 \lambda$ due to high coupling between dual element. The same scenario is observed for antenna isolation, where at $0.26 \lambda$, the isolation is becoming worse. In this preliminary works, the main focus is to reduce mutual coupling between dual element MIMO at the desired frequency. With these findings, the optimum antenna in this research works has been chosen at $0.32 \lambda$ distance between dual element due to its overall performance for future mobile MIMO application.

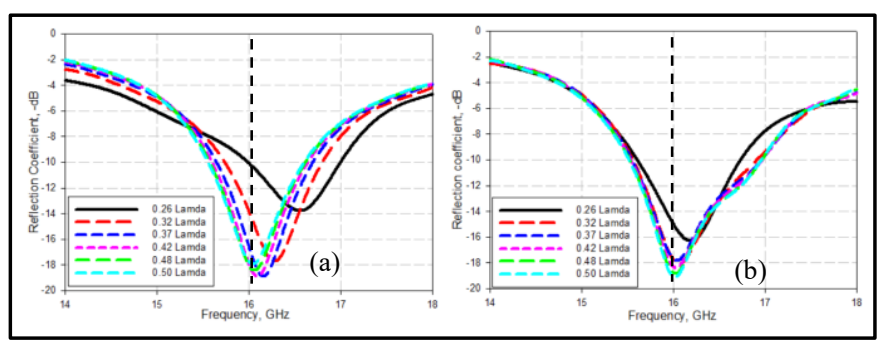

Fig. 3. Reflection coefficient (a)without (b) with parasitic element

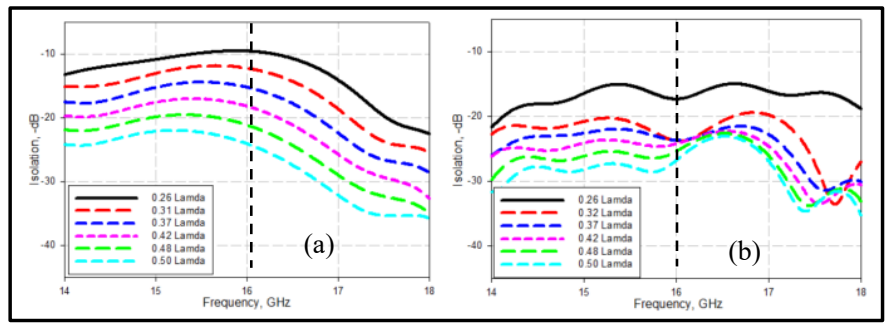

Fig. 4. Isolation (a) without and (b) with parasitic element

\section{ANALYSIS OF ANTENNA CURRENT DISTRIBUTION, ECC, DIVERSITY GAIN AND RADIATION PATTERN}

Dual MIMO antenna with acceptable isolation value[20] has been achieved through the selected element gap of $0.32 \lambda$ as shown in Figure 5(b). In this section, the implementation of a novel $\mathrm{C}$ shaped parasitic element for isolation improvement has been analyzed and studied through comparison with the original structure (without parasitic element) as shows in Figure 5(a). The purpose of adding the extra element around the main radiating patch is to create an indirect coupling path that opposes the signal going directly from one element to other element. If the two signal strengths are comparable, the two signals add up destructively resulting in the reduction of mutual coupling[21].

Meanwhile Figure 6 shows antenna performance in term of isolation for antennas design without and with parasitic element, respectively.

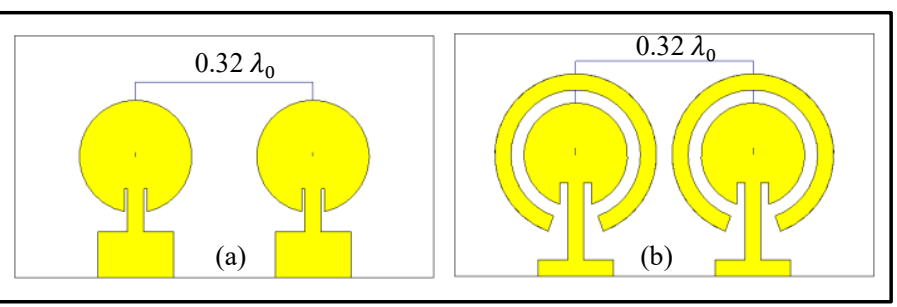

Fig. 5. Proposed antenna (a) without and (b) with $\mathrm{C}$ shaped parasitic element 


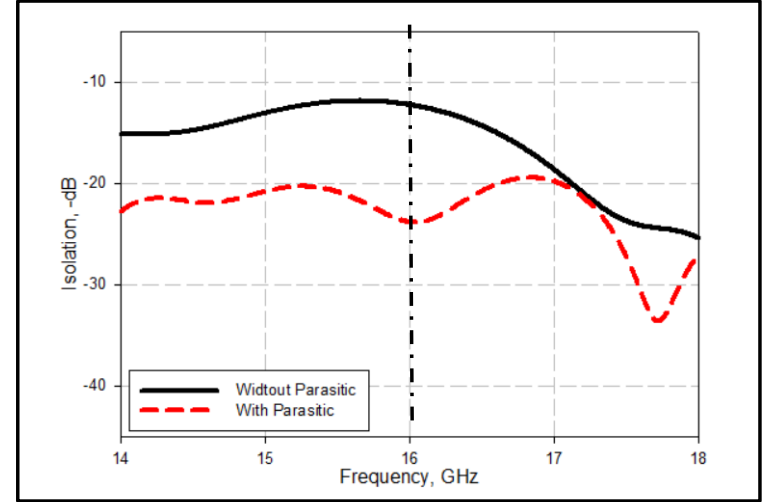

Fig. 6. Comparison of isolation -value for without and with $\mathrm{C}$ shaped parasitic element

From the isolation result, it can be concluded that by implementing the $\mathrm{C}$ shaped parasitic element, the isolation between MIMO elements can be improved. The dimension of the novel parasitic structure is taken as $\mathrm{W}=1 \mathrm{~mm}$. Based on the simulation result from Figure 6 , it can be observed that the isolation between dual element antenna has been improved from $-11.77 \mathrm{~dB}$ without parasitic element and $-23.92 \mathrm{~dB}$ on antenna with $\mathrm{C}$ shaped parasitic element structure. It shows an improvement of $25.79 \%$ for antenna with $\mathrm{C}$ shaped parasitic element as compared to antenna without parasitic element.

Meanwhile, Figure 7 and Figure 8 show the current distribution for both cases. As mentioned in[21], the reason for the reduction of mutual coupling between the antennas and the basic concept in justifying the final shape of the proposed antenna can be understood by analyzing the surface current distribution. The amount of mutual coupling between the two antennas in a MIMO system depends on the directions of the current flowing on the surface of the antennas. If the current flows in same direction on the adjacent sides of both the antennas, the mutual coupling is increased. However, if the currents are in opposite direction, the induced mutual coupling is reduced[22]. As observed from Figure 8, the current propagation on the right arm of the first antenna and parasitic structure placed around the antenna are flowing in the difference directions, thus minimizing the mutual coupling and improve the antenna isolation value.

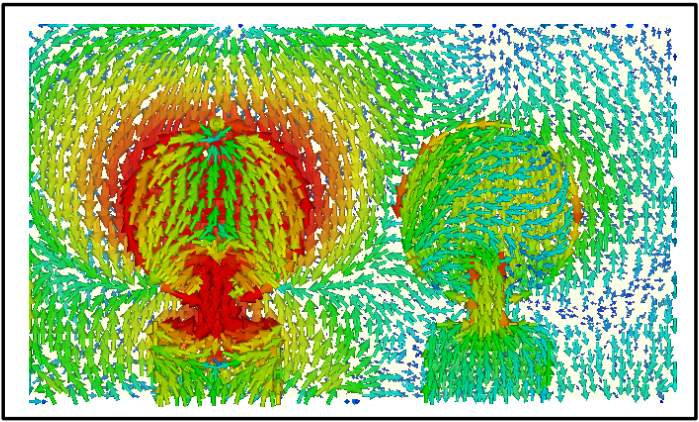

Fig. 7 Current distribution antenna without parasitic element

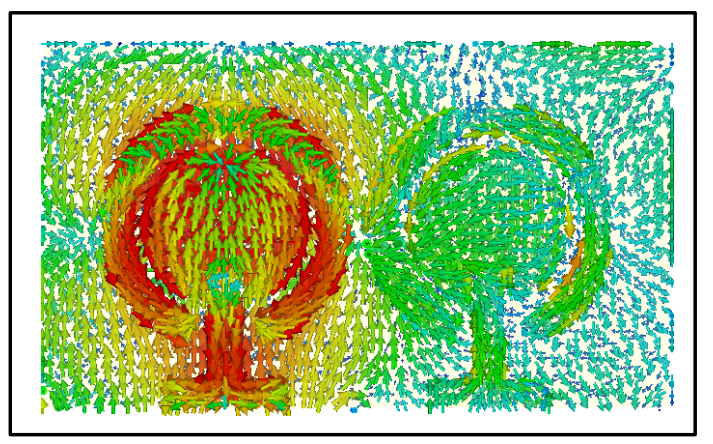

Fig. 8 Current distribution antenna with parasitic element

Further investigation on MIMO parameter has been conducted for both antenna structures. As mentioned in[23], other important parameter to evaluate MIMO performance is Enveloped Correlation Coefficient (ECC). This parameter is useful in estimating the diversity performance of a MIMO system. As mentioned in[24], the correlation coefficient value of 0.3 has been set as an acceptable value for MIMO technology. The ECC is calculated for both the MIMO systems, without and with parasitic element in between the antennas and is plotted in Figure 9. From the plot, it can be observed that the envelope correlation coefficient is very low at the selected resonant frequency, which indicates good isolation between the two antennas in the MIMO system. Meanwhile, Figure 10 shows the antenna diversity gain for both cases. Diversity is usually achieved when the transmitter receives multiple version of the transmitted stream through different channel path[25]. If the signals are uncorrelated, the combination signal at the receiver will provide higher SNR level and thus better signal reception[26] It shows that, both antennas agreed with maximum value of $10 \mathrm{~dB}[27]$ diversity gain. The simulation values are $9.99022 \mathrm{~dB}$, and $9.99916 \mathrm{~dB}$ at without and with parasitic element, respectively.

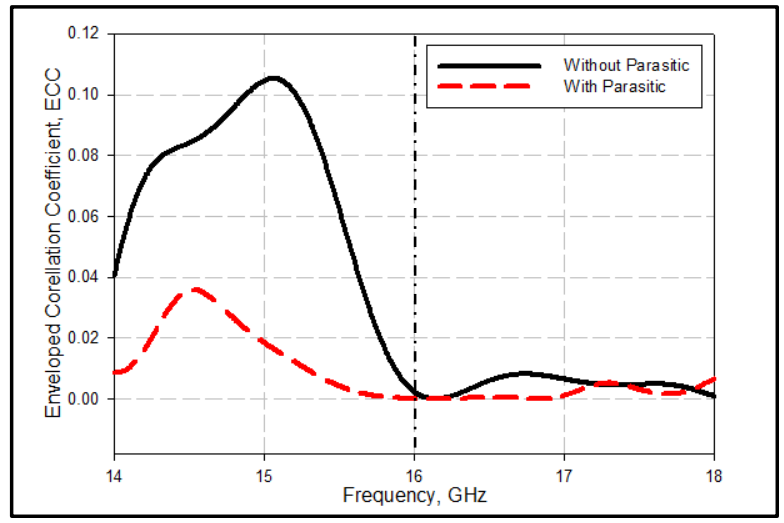

Fig. 9. Enveloped correlation coefficient 


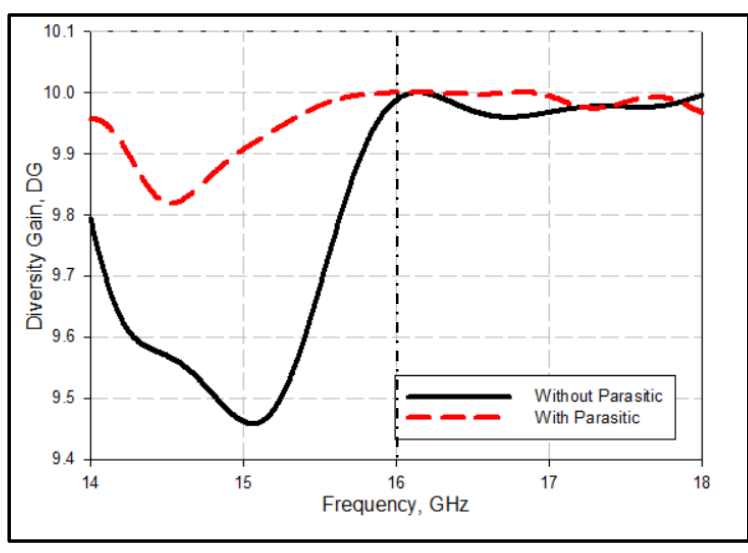

Fig. 10. Diversity gain

Good agreement in radiation pattern has been achieved for both configurations as shown in Figure 11 and 12. The figure shows the antenna normalized radiation patterns in E-plane and H-plane. Meanwhile, Figure 13 shows both cases of the antenna gain in 2D view. Then, Figure 14 and Figure 15 show the antenna radiation patterns in $3 \mathrm{D}$ views for all cases. The gain has been decreased as compared with the design without parasitic element. The result shows that the antenna gain for antenna without parasitic structure is $8.95 \mathrm{dBi}$, and for the antenna with parasitic structure, the gain has slightly reduced to $7.28 \mathrm{dBi}$. From the 3D view, it shows that the efficiency of antenna design with parasitic structure has been increased slightly from $65.8 \%$ to $80.4 \%$ compared with the antenna without parasitic structure. The bandwidth also has been increased from $1070 \mathrm{MHz}$ to $1420 \mathrm{MHz}$ when parasitic element is added.

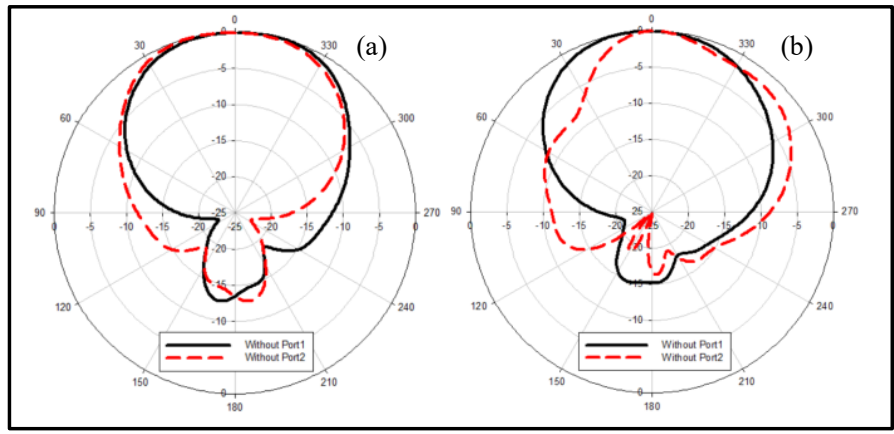

Fig. 11. Radiation Pattern without parasitic on port 1 and 2 for (a) Phi 0 (b) Phi 90

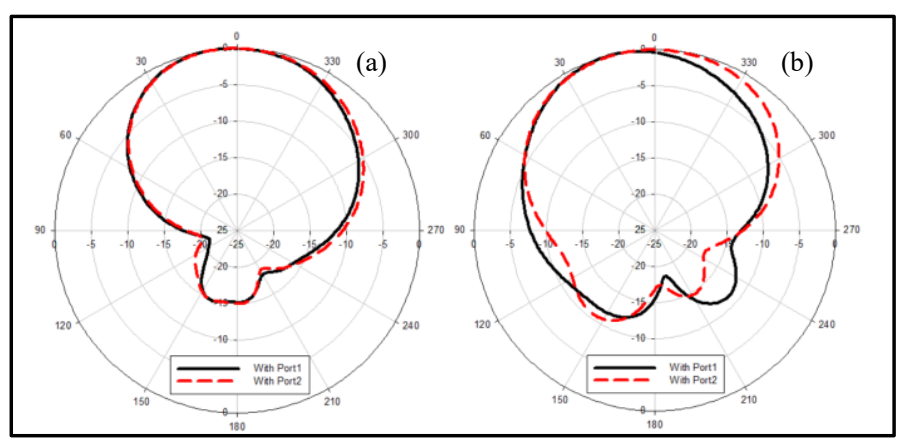

Fig. 12. . Radiation Pattern with parasitic on port 1 and 2 for (a) Phi 0 (b) Phi 90

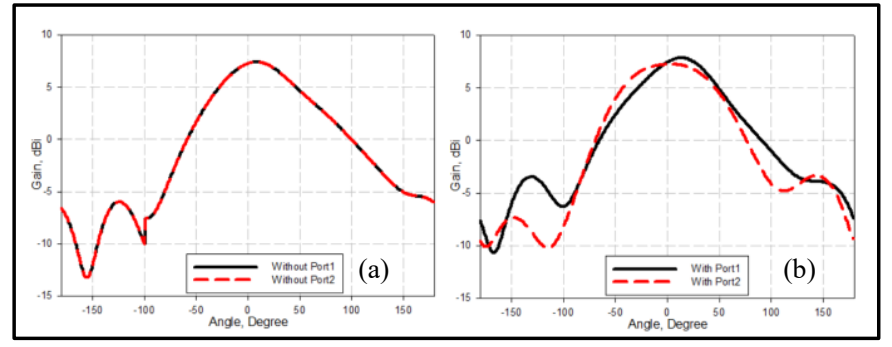

Fig. 13. Antenna gain port 1 and port 2 (a) Without (b) With parasitic element

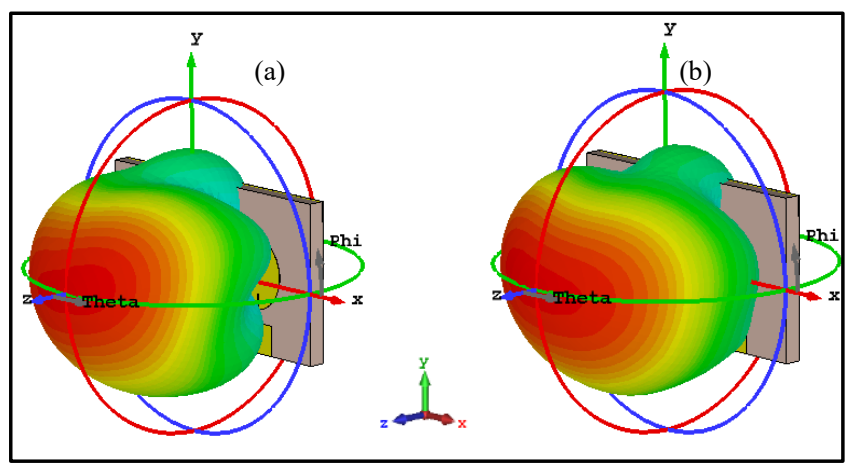

Fig. 14. Radiation Pattern 3D without parasitic (a) Port1 (b) Port2

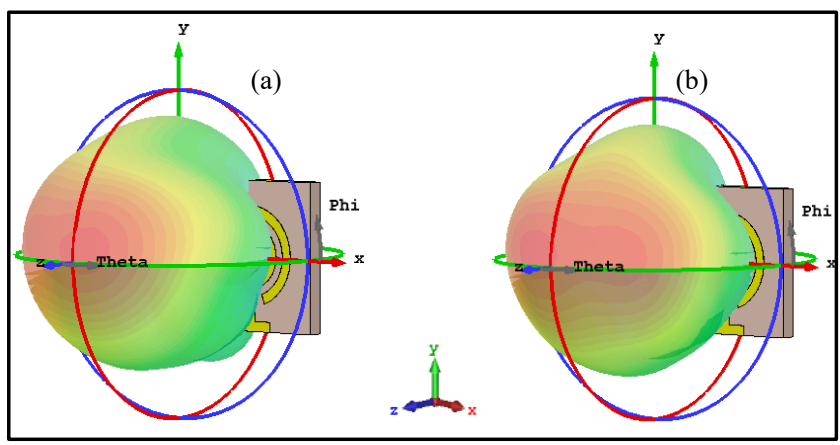

Fig. 15. Radiation Pattern 3D with parasitic (a) Port1 (b) Port2

Table 2 and table 3 show the comparison of the simulation results for antenna design without and with parasitic element. The improvement in MIMO has been analyzed and studied well. With this novel $\mathrm{C}$ shaped parasitic element, a new technique in reducing mutual coupling between multiple antennas has been validated to be able to improve antenna isolation and bandwidth. From the simulation result, it also shows that by locating parasitic element, the shifting in resonant frequency has been minimized. As a comparison to previous works, the effect of parasitic elements has been investigated in [28] and the concept of locating parasitic element above radiating patch has been introduced in [29], respectively. 
TABLE 2

ANTENNA WITHOUT PARASITIC ELEMENT

\begin{tabular}{lcc}
\hline Result & Port1 & Port2 \\
\hline Frequency (GHz) & 16.23 & 16.25 \\
Gain (dBi) & 8.95 & 8.95 \\
Reflection, & -18.60 & -17.32 \\
Coefficient & & \\
Efficiency (\%) & 65.8 & 66.7 \\
Isolation, (-dB) & -11.79 & -11.77 \\
ECC & 0.0008 & 0.0008 \\
Bandwidth & 1070 & 1070 \\
\hline
\end{tabular}

TABLE 3

ANTENNA WITH PARASITIC ELEMENT

\begin{tabular}{lcc}
\multicolumn{3}{c}{ ANTENNA WITH PARASITIC ELEMENT } \\
\hline Result & Port1 & Port2 \\
& & \\
\hline Frequency (GHz) & 16.05 & 16.05 \\
Gain (dBi) & 7.28 & 7.04 \\
Reflection, & -18.11 & -18.76 \\
Coefficient & & \\
Efficiency (\%) & 80.4 & 82.3 \\
Isolation, (-dB) & -23.92 & -24.06 \\
ECC & 0.00016 & 0.00016 \\
Bandwidth & 1420 & 1420 \\
\hline
\end{tabular}

\section{CONCLUSION}

The method and location of the parasitic structure to improve antenna isolation have been investigated and studied well in this research work. The ability of the proposed MIMO antenna that consists of two elements with parasitic structure has been validated toreduce mutual coupling between multiple antennas. This work has been verified by using electromagnetic simulator to determine the effectiveness of both structure. The parasitic element around on the top antenna structure has improved the antenna isolation with an improvement of $25.79 \%$ as compared to antenna without any parasitic element. Furthermore, by introducing the parasitic element the bandwidth have been improved by $32.71 \%$ when parasitic element is added

\section{ACKNOWLEDGMENT}

The authors would like to thank Universiti Teknologi MARA for sponsoring the work. Express gratitude to the members of the Antenna Research Center (ARC), Faculty of Electrical Engineering, Universiti Teknologi MARA for supporting the research work.

\section{REFERENCES}

[1] M. S. Sharawi, Printed MIMO Antenna Engineering. Artech House Antennas and Propagation, 2014.

[2] M. Nedil, "Coupling Reduction Between Dipole Antennas," IEEE ANTENNAS Propag. Mag., pp. 3-4, 2016.

[3] K. Qian and L. Zhao, "An Integrated Antenna Interference Cancellation Chip With Frequency Rejection Characteristic for MIMO Systems," IEEE Antennas Wirel. Propag. Lett., vol. 16, pp. $1285-1288,2017$

[4] D. Kumari, "Improved Isolation Between Antennas using Slotted Meander Line Structure for 5G Wireless Applications," Int. Conf. Comput. Commun. Electron., vol. 5880, pp. 312-314, 2017.

[5] Y. Li, W. X. Li, C. Liu, and T. Jiang, "Two UWB-MIMO antennas with high isolation using sleeve coupled stepped impedance resonators," 2012 IEEE Asia-Pacific Conf. Antennas Propagation,
APCAP 2012 - Proc., pp. 21-22, 2012

[6] M. T. Islam and M. S. Alam, "Compact Ebg Structure for Alleviating," Prog. Electromagn. Res., vol. 137, no. February, pp. 425-438, 2013.

[7] D. S. Chandu, S. S. Karthikeyan, and K. V. Phani Kumar, "Reduction of mutual coupling in a two element patch antenna array using subwavelength resonators," 2015 21st Natl. Conf. Commun. NCC 2015, 2015.

[8] S. Dumanli, D. R. Gibbins, and I. J. Craddock, "A Wide Band MIMO Slot Antenna for 5G Wi-Fi," IEEE Trans. Antennas Propag., vol. 1, pp. 1226-1227, 2015.

[9] Y. Wang and Z. Du, "A wideband printed dual-antenna with three neutralization lines for mobile terminals," IEEE Trans. Antennas Propag., vol. 62, no. 3, pp. 1495-1500, 2014.

[10] S. Lim, W. C. Choi, Y. J. Yoon, and C. You, "An Isolation Technique for Closely Stacked MIMO Antennas,” Proc. ISAP, vol. 1, no. c, pp. 356-357, 2016.

[11] M. Li, Z. Xu, Y. Ban, C. Sim, and Z. Yu, "Eight-port orthogonally dual-polarised MIMO antennas using loop structures for $5 \mathrm{G}$ smartphone," Inst. Eng. Technol., vol. 11, no. 12, pp. 1810-1816, 2017.

[12] J. Iqbal, U. Illahi, M. I. Sulaiman, M. M. Alam, M. M. Suud, and M. N. Mohd Yasin, "Mutual Coupling Reduction Using Hybrid Technique in Wideband Circularly Polarized MIMO Antenna for WiMAX Applications," IEEE Access, vol. 7, no. c, pp. 40951-40958, 2019

[13] R. L. Xia, S. W. Qu, P. F. Li, Q. Jiang, and Z. P. Nie, "An Efficient Decoupling Feeding Network for Microstrip Antenna Array," IEEE Antennas Wirel. Propag. Lett., vol. 14, no. c, pp. 871-874, 2015.

H. Z. H. Qi, X. Yin, "A hybrid solution for mutual coupling reduction between closely spaced microstrip antennas," IEEE Trans. Antennas Propag., 2015.

[15] R. Hussain, A. T. Alreshaid, S. K. Podilchak, and M. S. Sharawi, "Compact 4G MIMO antenna integrated with a 5G array for current and future mobile handsets," pp. 271-279, 2016.

[16] S. W. Cheung, Q. Li, D. Wu, C. Zhou, and B. Wang, "Defected Ground Structure with Two Resonances for Decoupling of Dual-band MIMO Antenna," IEEE Antennas Wirel. Propag. Lett., pp. 16451646,2017

[17] O. F. Ahmed, "Mutual Coupling Reduction of MIMO Antennas using Parasitic Elements for Wireless Communications," Int. J. Comput. Appl., vol. 62, no. 19, pp. 39-42, 2013.

[18] M. Issues, M. Spectrum, B. Cyberjaya, T. M. Communications, M. Commission, and S. Srsp-, "For Immediate Release MCMC Issues the Revised Standard Radio System Plan in Preparation for the Introduction of $4 \mathrm{G}$ Services in the $2600 \mathrm{MHz}$ Spectrum Band Cyberjaya : 29 November, 2012 --- The Malaysian Communications and Multimedia Commission ( MCMC ) ha," no. Mcmc, pp. 3-5, 2012.

[19] Malaysian Communications and Multimedia Commission, "RADIO SPECTRUM ALLOCATIONS IN MALAYSIA,” no. April, 2017, p. 200.

[20] B. Baharom, M. T. Ali, H. Jaafar, and H. Yon, "Dual-Element of high-SHF PIFA MIMO Antenna for Future 5G Wireless Communication Devices," Proc. - 2018 Int. Symp. Antennas Propag., no. ISAP, pp. 151-152, 2018.

[21] P. S. Kumar and B. C. Mohan, "Design of a compact two element MIMO antenna with improved bandwidth and isolation," 2015 Int. Conf. Microwave, Opt. Commun. Eng. ICMOCE 2015, pp. 389-392, 2016.

[22] J. Hwang and S. Chung, "Isolation Enhancement Between Two Packed Antennas With Coupling Element," IEEE Antennas Wirel. Propag. Lett., vol. 10, pp. 1263-1266, 2011.

[23] M. Lin, P. Liu, and Z. Guo, "Gain-enhanced Ka-band MIMO antennas based on the SIW corrugated technique," IEEE Antennas Wirel. Propag. Lett., vol. 16, no. October, pp. 3084-3087, 2017.

[24] M. Ikram, R. Hussain, and M. S. Sharawi, "Low profile 6-element modified-monopole MIMO antenna system for mobile applications," 2016 IEEE Int. Symp. Antennas Propag., pp. 73-74, 2016.

[25] M. S. Sharawi, M. Ikram, and A. Shamim, "A Two Concentric Slot Loop Based Connected Array MIMO Antenna System for 4G/5G Terminals," IEEE Trans. Antennas Propag., vol. 65, no. 12, pp. 6679-6686, 2017.

[26] M. S. Sharawi, "Printed Multi-band MIMO Antenna Systems : 
Techniques and Isolation Mechanisms," vol. 1, no. EuCAP, pp. 779783, 2014.

[27] I. K. Cheh Lin et al., "A Triple Band Hybrid MIMO Rectangular Dielectric Resonator Antenna for LTE Applications," IEEE Access, vol. 7, pp. 122900-122913, 2019.

[28] S. Kumar, S. Srivastava, A. D. Pandey, and M. R. Tripathy, "Design of Miniaturized Fractal Antenna on Two Layer Stack," IEEE ANTENNAS Propag. Mag., vol. 3, no. 8, pp. 91-96, 2014.

[29] W. Hong, A. Goudelev, K. Baek, V. Arkhipenkov, and J. Lee, “24Element Antenna-in-Package for Stationary 60-GHz Communication Scenarios," Prog. Electromagn. Res. B, vol. 10, pp. 738-741, 2011.

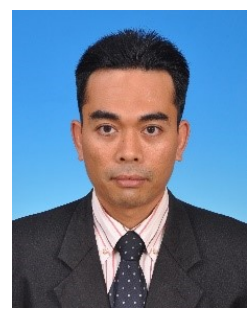

Hamizan Yon was born in Muar Johor on February 07, 1980. He received the Bachelor Information Technology with Network Computing in 2013. In 2018, he completed his Master in Electrical Engineering (Communication) with Antenna Research Centre (ARC) Faculty of Electrical Engineering, Universiti Technologi MARA. Now he pursuing his Ph.D at Antenna Research Centre (ARC) Faculty of Electrical Engineering, Universiti Technologi MARA. In 2009 he joined Universiti Teknologi MARA at Shah Alam campus as assistant lecturer. In 2018, he has appointed as full Lecturer after completed his Master. Active in research activates, he is one of the members of fundamental research grant (FRGS) under Minister of Higher Education and UiTM Lestari grant. As academician, Hamizan also is a member of The Institution of Engineering and Technology (IET) that actively presenting and publishing research activities at national and international levels.

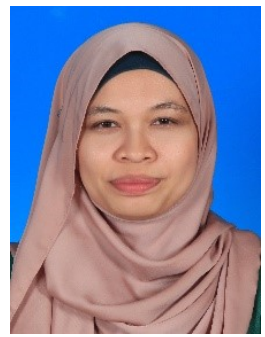

N. H. ABD RAHMAN (M'15) obtained her M. Eng. in Electronic from University of Surrey, Guildford, United Kingdom in 2008 and a Ph.D in Electric, Electronic and Systems Engineering from Universiti Kebangsaan Malaysia (UKM), Bangi, Malaysia in 2014. Her Ph.D work was on designing and analyzing satellite-mount parabolic reflector antenna for Malaysia beam coverage by adopting ray-tracing method. This project was a collaboration between UKM and the National Defense Academy, Yokosuka, Japan. In 2014, she was appointed as a senior lecturer in Universiti Teknologi MARA Malaysia (UiTM). She has work experience in the field of satellite and communication engineering. In 2008, she joined Astronautic Technology (M) Sdn. Bhd. (known as $\mathrm{ATSB}^{\circledR}$ ) as a spacecraft engineer. At $\mathrm{ATSB}^{\circledR}$, she was involved in various small-class satellite development projects such as CubeSAT and InnoSAT, and an R\&D project related to satellite X-band transmission system. She was also involved in mission definition study for national communication satellite project. She has experiences in modelling, designing and developing RF and communication modules, specifically antennas and RF transmitters. Currently, she is a postdoctorate fellow at Malaysia-Japan International Institute of Technology, Universiti Teknologi Malaysia (MJIIT-UTM) Kuala Lumpur.
She has received several research grants in wearable antennas, lens and reflector antennas, and other communication-related areas, obtained from government and the university. Currently, she is supervising several postgraduate and undergraduate students. She has published more than 50 scientific papers in indexed journals and conference proceedings. In addition, she is also active in reviewing research articles for several journals related to antennas and propagation. Her current research interests include antennas for space and terrestrial applications, array antennas, reflector and lens antennas, wearable and flexible antennas, RF and microwave design and electromagnetic analysis.

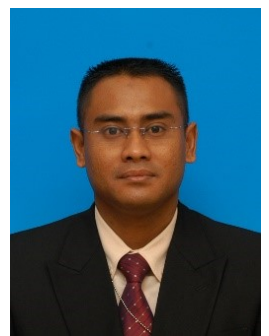

Mohd Aziz Aris was born in Semporna Sabah in 1975. He received the Diploma in electrical engineering from Universiti Teknologi MARA Shah Alam in 1999. In 2003, he received the B. Eng degree (Hons) in electrical engineering (Communication) and the master degree in 2006 from Universiti Teknologi MARA Shah Alam. Now he completed his $\mathrm{PhD}$ in electrical engineering (Communication) with Antenna Research Center (ARC) faculty of electrical engineering Universiti Teknologi MARA. In 2006 In 2006 he join Universiti Teknologi MARA at Terengganu Campus after completed his master. Active in research activities, he received three foundamental research grant scheme (FRGS) under Ministry of Higher Education to lead the research on antenna design and nondestructive material measurement for RF applications. As academician, Mohd Aziz also member of Institute of Electrical Electronic Engineering Society (IEEE) that actively presenting and publishing research activities at national and internationals level. During pursuing his $\mathrm{PhD}$, he also received the award title as an innovative and dedicated technological researcher based on his contribution in research and ideas.

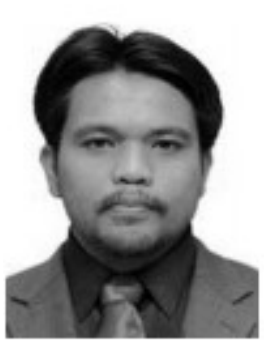

MOHD HAIZAL JAMALUDDIN received the bachelor's and master's degrees in electrical engineering from Universiti Teknologi Malaysia (UTM), Malaysia, in 2003 and 2006, respectively, and the Ph.D. degree in signal processing and telecommunications from the Université de Rennes 1, France, in 2009 , with a focus on microwave communication systems and specially antennas, such as dielectric resonator and reflectarray and dielectric dome antennas. He is currently an Associate Professor with the Wireless Communication Centre, School of Electrical Engineering, UTM. He has published more than 100 articles in reputed indexed journals and conference proceedings. His research interests include dielectric resonator antennas, printed microstrip antennas, MIMO antennas, and DRA reflectarray antennas. 


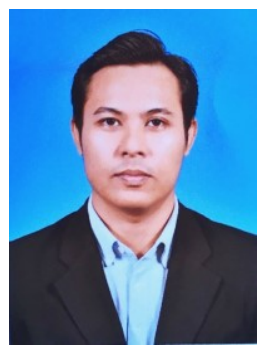

Hadi Jumaat received the B. Eng. in engineering electronics and M.Sc. degree in electrical engineering from the Universiti Teknologi MARA (UiTM), Selangor, Malaysia in 2012 and 2015. He is currently working towards the $\mathrm{Ph}$. D. degree in electrical engineering at Antenna Research Center (ARC) in Universiti Teknologi MARA. Since 2015, he joined UiTM as a lecturer. His research interests are in communication antenna design, biomedical antenna and electromagnetic wave propagation. 